\title{
A Comparative Study of Biocompatibility and Marginal Adaptability of MTA, Biodentine, and Glass Ionomer Cement as Root -End Filling Materials (Comparative In-Vitro Study)
}

\author{
Mohammed Awadd Ali ${ }^{1 *}$, Maged M Negm² and Heba AEl-Asfouri ${ }^{3}$ \\ ${ }^{1}$ Masters Student, Endodontic department, Faculty of Dentistry, Cairo University, \\ Egypt \\ ${ }^{2}$ Professor of Endodontics, Faculty of Dentistry, Cairo University, Egypt \\ ${ }^{3}$ Associate Professor of Endodontics, Faculty of Dentistry, Cairo University, Egypt \\ *Corresponding Author: Mohammed Awadd Ali, Masters Student, Faculty of \\ Dentistry, Cairo University, Egypt
}

Received: December 08, 2020

Published: December 28, 2020

(C) All rights are reserved by Mohammed

Awadd Ali., et al.

\begin{abstract}
Aim: The aim of the present study was to compare the in vitro biological behavior and marginal adaptability of MTA, Biodentine and glass-ionomer cement as retrograde filling materials.

Methodology: The biocompatibility test was made on fibroblast cells regarding cell viability. The cells were exposed to the extracts of the materials of 1, 5 and 7 days to measure cell viability using MTT assay. Regarding marginal adaptability twenty-four singlerooted teeth were resected $3 \mathrm{~mm}$ from the apex. Root-end cavities were then prepared using a fissure bur and filled with one of the following materials Glass ionomer cement (GIC), Mineral trioxide aggregate (MTA) and a bioactive cement Biodentine. The roots were then sectioned longitudinally. Scanning electron microscope (SEM) was used to determine area of gaps and adaptation of the root-end filling materials with the dentin.

Results: Results showed that Biodentine and MTA maintained favorable cell viability compared with GIC over the three observation points, also Biodentine and MTA exhibited the lowest marginal gaps than GIC that showed the least adaptation with largest marginal gaps.

Conclusion: MTA and Biodentine display good cytocompatibility with normal fibroblast cells, both did not significantly affect cell proliferation and can be classified as biocompatible retrograde filing materials, While GIC significantly affect fibroblast proliferation and should be used with caution.
\end{abstract}

Concerning marginal adaptability, MTA and Biodentine showed less micro-gaps with the dentinal walls compared with GIC and they can be used successfully as retrograde filling materials.

Keywords: MTA; Biodentine; GIC; MTT; Biocompatibility; Marginal Adaptability

\section{Introduction}

The presence of endodontic microbiota and biofilms in inaccessible areas cause failure in endodontic treatment [1]. When nonsurgical root canal treatment fails to treat periradicular lesions of endodontic origin, surgical endodontic treatment is preferred [2]. The significant factor in the success of surgical endodontic treatment is to achieve a decent seal between the tooth and root-end filling material.
Several root-end filling materials have been introduced such as amalgam, Cavit, composite resins, gutta-percha, intermediate restorative material (IRM), zinc oxide and eugenol cement, super ethoxy benzoic acid (EBA), mineral trioxide aggregate (MTA), biodentine (BD), and EndoSequence [3]. Marginal adaptation of retrograde materials is very important for endodontic surgery success. This property will determine whether the material is suitable for clinical use or not [4]. Marginal adaptation mirrors the sealing abil- 
ity of a root-end filling material; in this manner, it has been considered as an important property [5]. The viability of periradicular cells may be compromised because of the cytotoxicity of materials utilized during the methods of repair of perforations and retrograde filling. These materials may cause apoptosis or necrosis of the cells and so need to be biologically inert [6].

MTA shows great cytocompatibility results; however, its handling and setting time are not ideal. Recently, new materials have been introduced to overcome the downsides of $\mathrm{MTA}^{(6)}$.

Biodentine (BD) is calcium silicate cement with dentin-like properties, which has been recommended as an option in contrast to MTA. A pervious study found that the measures of calcium ions delivered from BD is greater than that delivered from MTA with comparable effect in the clinical setting and induced the same response of the pulp-dentin complex in human teeth [6].

So the purpose of this study was to compare the biocompatibility and marginal adaptability of MTA CEM, Biodentine and glassionomer cement as retrograde filling materials.

\section{Materials and Methods}

\begin{tabular}{|c|c|}
\hline $\begin{array}{l}\text { Biodentine (BD) } \\
\text { (Septodont, Saint } \\
\text { Maur Des Fosses } \\
\text { France) }\end{array}$ & $\begin{array}{l}\text { An inorganic, non-metallic compound in- } \\
\text { troduced in capsulated powder and liquid } \\
\text { structure. The powder phase consists of trical- } \\
\text { cium silicate (main core material), dicalcium } \\
\text { silicate, calcium carbonate, calcium oxide, iron } \\
\text { dioxide and zirconium dioxide (acts as radio- } \\
\text { opacifier).The liquid phase combines calcium } \\
\text { chloride, water and a water reducing agent. } \\
\text { The setting time of Biodentine is } 12 \text { mins. }\end{array}$ \\
\hline $\begin{array}{r}\text { MTA } \\
\text { (Nexob }\end{array}$ & $\begin{array}{c}\text { A powder of fine, hydrophilic particles that set } \\
\text { in combination with water. Hydration of the } \\
\text { powder creates a colloidal gel that sets to form } \\
\text { a solid impermeable barrier and shows quick } \\
\text { setting time. }\end{array}$ \\
\hline $\begin{array}{l}\text { Medifil glass } \\
\text { ionomer cement } \\
\text { (Promedica, } \\
\text { Neumünster, } \\
\text { Germany) }\end{array}$ & $\begin{array}{l}\text { A glass ionomer filling cement contains fluro- } \\
\text { silicate glass, polyacrylic acid and parbenes. } \\
\text { It is characterized by having excellent bio- } \\
\text { compatibility, low acidity, no temperature rise } \\
\text { during setting, self-adhesion to dentine and } \\
\text { enamel, high compressive strength and excel- } \\
\text { lent radiopacity. It has a setting time of } 6 \text { mins. }\end{array}$ \\
\hline $\begin{array}{l}\text { Adseal (Meta } \\
\text { Biomed, } \\
\text { Cheongju, } \\
\text { South Korea) }\end{array}$ & $\begin{array}{l}\text { Resin based root canal sealer composed of: } \\
\text { Base (Epoxy resin, Calcium phosphate) and } \\
\text { catalyst (Amines, Bismuth subcarbonate).It } \\
\text { has working time of } 35 \text { mins. And sets after } 45 \\
\text { mins. At } 37^{\circ} \mathrm{C} .\end{array}$ \\
\hline
\end{tabular}

Table 1: Materials used in this study.

\section{Biocompatibility test}

\section{Description of samples}

Normal fibroblasts cell line "BHK" (ATCC, Manassas, USA) was obtained from the American Type Culture Collection, and maintained at the Egyptian National cancer Institute, Cairo, Egypt.

Determination of cellular proliferation using MTT tetrazolium assay

\section{Principle}

Cytotoxicity of the materials was determined using the MTT [(3(4, 5-dimethylthiazole-2-yl)-2, 5- diphenyltetrazolium bromide)]. The method depends on the capacity of dynamic mitochondrial dehydrogenase enzyme of the living cells to split the tetrazolium rings of the yellow MTT and make them dim blue insoluble formazan crystals which cannot pass the cell membranes, resulting in its accumulation within healthy cells. The number of viable cells is directly proportional to the strength of soluble Formosan dark blue $\operatorname{color}^{(7)}$

\section{Manipulation of materials and specimens preparation}

Specimens were manufactured in sterile conditions to avoid disinfecting them before cell-culture testing. Each material was prepared according to manufacturer's instructions. Material's heavy consistency after mixing enabled its manipulation, it was carried with a small spatula from the capsule into the Teflon mould (Figure 1) with dimensions of $2 \times 4 \mathrm{~mm}$ which was placed on sterile glass slab, and permitted to set at room temperature prior to testing.

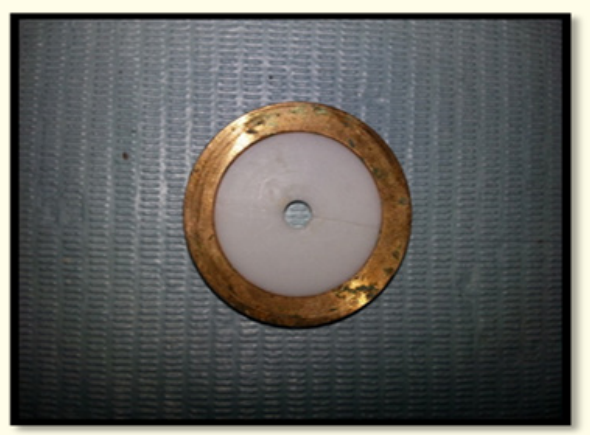

Figure 1: Teflon mold. 
A Comparative Study of Biocompatibility and Marginal Adaptability of MTA, Biodentine, and Glass Ionomer Cement as Root -End Filling Materials (Comparative In-Vitro Study)

Material discs were then removed from Teflon molds and tested for cytotoxicity in indirect contact, by preparing an extract of the material through immersion in extraction media, and then obtained extracts were transferred into cultured cells and incubated at $37^{\circ} \mathrm{C}$ for 1 day, 5 days and 7 days.

Normal fibroblasts cell line "BHK" was obtained frozen in liquid nitrogen from the American Type Culture Collection, then maintained by serial sub-culturing in National Cancer Institute. Cells obtained were seeded in 24-well microtiter plates (Figure 2) at a concentration of $5 \times 10^{3} \mathrm{BHK}$ cells/ well in a $150 \mu \mathrm{l}$ fresh medium. It was incubated for $24 \mathrm{hrs}$. in a high humidity atmosphere in the water jacketed incubator (Revco, GS laboratory equipment, RCO 3000 TVBB, USA.).

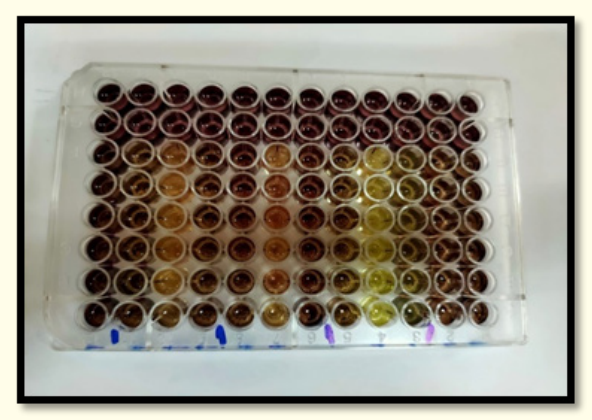

Figure 2: Microtiter plates containing BHK cell lines with the extraction media.

Extracts of each material were prepared as follows: $600 \mu \mathrm{l}$ of culture medium was placed in each well containing the freshlymixed materials (ratio of surface area exposed to volume of extract vehicle $=190 \mathrm{~mm} 2 / 600 \mu \mathrm{l}=316 \mathrm{~mm} 2 / \mathrm{ml}$ ). Extraction media of the materials were collected at three observation points corresponding to the following assigned durations of extraction: 1 day (after the first 1 day of extraction), 5 days (starting after 1 day up to 5 days) and 7 days (starting after 5 days up to 7 days). Untreated controls, were cells cultured with media free of the materials' components.

After incubation for $4 \mathrm{hrs} 100 \mu \mathrm{l}$ of $10 \%$ SDS in 0.01 NaHCL was added to each well. The solution was allowed to solubilize over- night in $100 \%$ humidity. The photometric determination of the absorbance was achieved at $570 \mathrm{~nm}$ using micro plate ELISA reader (TECAN (Austria Gmbh). Data were compared with the control group.

\section{Calculation}

The percentage of cell survival was calculated as follows:

Survival fraction = optical density (O.D) (treated cells) $/ 0 . D$ (control cells).

Determination of marginal adaptability using SEM

Sample selection

Twenty-four freshly extracted human single canalled teeth were collected from patients of the dental clinic of the National Diabetes and Endocrinology institute, Cairo - Egypt. Teeth were free from root caries, root fractures or root resorption and excluded if radiographs revealed multiple root canals or severe root-end curvature. Sample preparation

Teeth were decoronated at the level of cemento-enamel junction into a standardized length of $15 \mathrm{~mm}$ and the canals were negotiated with K-file size 10 (Mani Inc., Tochigi, Japan) to provide patency and then the working length was adjusted at $1 \mathrm{~mm}$ shorter after the first inspection of the file at the apex.

Mechanical preparation was made with Protaper Universal files (Dentsply, Tulsa Dental, Tulsa, OK, USA) with a speed of 350 rpm and torque $2 \mathrm{Ncm}$ using X-Smart Plus endo motor (Dentsply Maillefer, Ballaigues, Switzerland). Apical preparation was done up to size 30 (F3) in accordance to the type of the tooth and irrigated with $2.5 \%$ sodium hypochlorite between each instrumentation cycle and the next, using a syringe and a side-vented 30 gauge needles that positioned at $1 \mathrm{~mm}$ shorter from the adjusted working length. The final rinse was performed with $2 \mathrm{ml}$ of $17 \%$ ethylenediaminetetraacetic acid (EDTA) for two minutes then flushed with $2.5 \% \mathrm{NaOCl}$ to remove the smear layer and dentine mud. Teeth were irrigated with saline and cold lateral condensation obturation technique was conducted using Adseal root canal sealer (Meta Biomed, Cheongju, South Korea). After obturation, the teeth were left in humid environment for 2 days to avoid fracture during the cutting procedures. 
A Comparative Study of Biocompatibility and Marginal Adaptability of MTA, Biodentine, and Glass Ionomer Cement as Root -End Filling Materials (Comparative In-Vitro Study)

A 3-mm portion of the root-end of each tooth was removed perpendicular to the long axis using a diamond bur (Dentsply/ Maillefer, Tulsa, Okla.) under water coolant. Retro-cavities, with 1 $\mathrm{mm}$ width and $3 \mathrm{~mm}$ depth, were prepared with a fissure bur in a high-speed handpiece.

The cavities were retrofilled with the mixed materials using a carrier (Premier Dental, King of Prussia, PA, USA) and condensed with a plugger (Dentsply Maillefer, Ballaigues, Switzerland).

The teeth were kept in a humid condition at room temperature for one day to permit total setting of the materials then by the use of a low-speed grinding disc (Labcut Agar Scientific, Cambridge, UK), the retrofilled roots were cut longitudinally into two equal halves. Each half was assessed under SEM (S360, Oxford Co., Cambridge, UK) at a $\times 1000$ magnification. To assess the marginal adaptation between the filling materials and dentine walls, the maximum value of width and length of gaps in each half was identified and recorded separately. Finally, the mean overall gap was calculated for each group separately by taking the mean of their combined (additive) mean length and mean width.

\section{Results}

Biocompatibility test

\section{Viability at 1 day}

Between the three groups

In group A (Biodentine), the mean and standard deviation values of viability were $(163.04 \% \pm 13.83 \%)$, while in group B (MTA) they were $(84.93 \% \pm 7.57 \%)$ and in group C (GIC) they were $(40.09 \% \pm 4.32 \%)$. There was a statistically significant difference between the three groups ( $\mathrm{p}<0.001)$ (Table 2).

\section{Viability at 5 days}

Between the three groups

In group A (Biodentine), the mean and standard deviation values of viability were $(105.45 \% \pm 9.81 \%)$, while in group B (MTA) they were $(99.29 \% \pm 11.8 \%)$ and in group C (GIC) they were $(53.46 \% \pm 9.15 \%)$. There was a statistically significant difference between the three groups ( $<<0.001)$ (Table 3).

\begin{tabular}{|c|c|c|c|c|}
\hline & Group A & Group B & Group C & P-Value \\
\hline Mean & 163.04 & 84.93 & 40.09 & \\
\hline SD & 13.83 & 7.57 & 4.32 & $<0.001^{*}$ \\
\hline
\end{tabular}

Table 2: Means, standard deviations (SD) and the results of ANOVA test for comparison of viability between the three groups.

\begin{tabular}{|c|c|c|c|c|}
\hline & Group A & Group B & Group C & P-Value \\
\hline Mean & 105.45 & 99.29 & 53.46 & \\
\hline SD & 9.81 & 11.80 & 9.15 & $<0.001^{*}$ \\
\hline
\end{tabular}

Table 3: Means, standard deviations (SD) and the results of ANOVA test for comparison of viability between the three groups.

\section{Viability at 7 days}

Between the three groups

In group A (Biodentine), the mean and standard deviation values of viability were $(89.74 \% \pm 15.3 \%)$, while in group B (MTA) they were $(110.58 \% \pm 14.81 \%)$ and in group C (GIC)they were $(52.99 \% \pm 6.01 \%)$. There was a statistically significant difference between the three groups $(\mathrm{p}<0.001)$ (Table 4$)$.

\begin{tabular}{|c|c|c|c|c|}
\hline & Group A & Group B & Group C & P-Value \\
\hline Mean & 89.74 & 110.58 & 52.99 & \\
\hline SD & 15.30 & 14.81 & 6.01 & $<0.001^{*}$ \\
\hline
\end{tabular}

Table 4: Means, standard deviations (SD) and the results of ANOVA test for comparison of viability between the three groups.

Cell viability of the materials at the three-different observation points

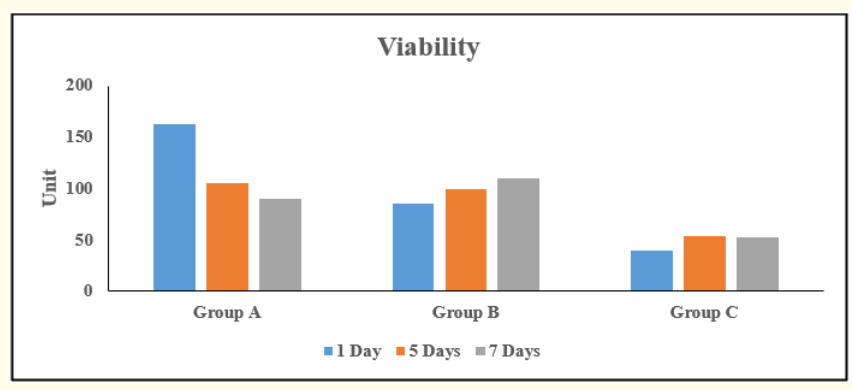

Figure 3: Column chart showing the cell viability ratio of the materials at the Three observation points. 
A Comparative Study of Biocompatibility and Marginal Adaptability of MTA, Biodentine, and Glass Ionomer Cement as Root -End Filling Materials (Comparative In-Vitro Study)

\begin{tabular}{|c|c|c|c|c|}
\hline & Group A & Group B & Group C & P-Value \\
\hline 1 Day & 163.04 & 84.93 & 40.09 & $<0.001^{*}$ \\
\hline 5 Days & 105.45 & 99.29 & 53.46 & $<0.001^{*}$ \\
\hline 7 Days & 89.74 & 110.58 & 52.99 & $<0.001^{*}$ \\
\hline
\end{tabular}

Table 5: Table showing mean viability comparison between the three groups after 1, 5 and 7 days.

\section{Marginal adaptability test}

Between the three groups

In group A (Biodentine), the mean and standard deviation values of marginal gap were $(7.68 \pm 1.8) \mu \mathrm{m}$, while in group B (MTA) they were $(8.04 \pm 1.27) \mu \mathrm{m}$ and in group C (GIC) they were $(16.08 \pm$ $1.66 \%) \mu \mathrm{m}$. There was a statistically significant difference between the three groups $(\mathrm{p}<0.001)$ (Table 6).

\begin{tabular}{|c|c|c|c|c|}
\hline & Group A & Group B & Group C & P-Value \\
\hline Mean & $7.68 \mu \mathrm{m}$ & $8.04 \mu \mathrm{m}$ & $16.08 \mu \mathrm{m}$ & \\
\hline SD & 1.80 & 1.27 & 1.66 & $<0.001^{*}$ \\
\hline
\end{tabular}

Table 6: Means, standard deviations (SD) and the results of ANOVA test for comparison of marginal gap between the three groups.

*Significant at $\mathrm{p}<0.05$.

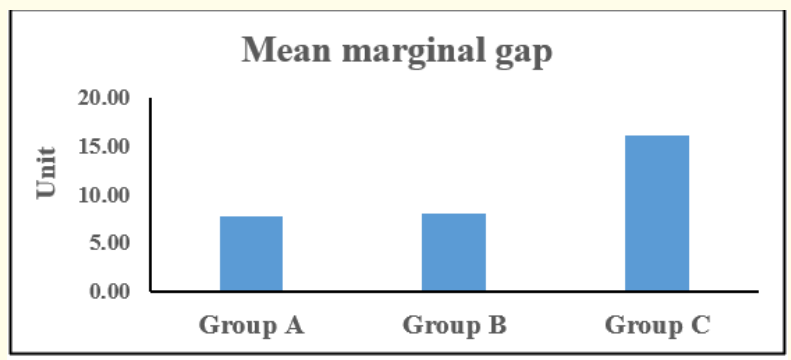

Figure 4: Bar chart representing the mean marginal gap in the three groups. 
A Comparative Study of Biocompatibility and Marginal Adaptability of MTA, Biodentine, and Glass Ionomer Cement as Root -End Filling Materials (Comparative In-Vitro Study)

often is a significant problem when performing experiments in vivo. The MTT assay is the most commonly used test for assessing the cytotoxicity of materials against different cell lines including the gingival fibroblasts, DPSCs, SCAP, and the periodontal ligament fibroblasts. This assay is a standard ISO-approved method for assessment of cytotoxicity [8].

Curiously, in our investigation, cell contact with BD for 1 day indicated an expansion in the proportions of living cells in contrast to GIC. Comparative discoveries were not seen with MTA. This outcome could be clarified by the distinctions in constitutes between BD and MTA. One of the distinctions is the radiopacifier. On account of MTA, the radiopacifier is bismuth oxide, while for BD it is zirconium oxide. The utilization of bismuth oxide in MTA has been shown that it doesn't advance cell growth [9].

Similar fibroblasts cell growth was observed after 5 days when comparing BD and MTA. Comparative outcomes have been accounted by Zhou., et al. (2013). when measuring cell growth of human gingival fibroblasts presented to extracts of BD and MTA [10].

Our outcomes concerning the biocompatibility measures revealed that MTA introduced higher cytocompatibility and low toxicity following 7 days compared to BD. It is likewise critical that longer incubations with the extracts of MTA offered an increase in cell growth. These outcomes are steady with other reported studies which demonstrated that MTA may prompt an expansion in poliferation of exact types of dental cells [11]. This could also be due to the differences of $\mathrm{pH}$ and calcium ion release between the materials [12]. These outcomes are also in a way that agrees with Liu., et al. (2007) who found that the cell viability of human bone marrow stromal cells (hBMSCs) increased gradually with time on $\beta$-tricalcium phosphate scaffold during the first week, peaked at the seventh day [13].

In the current study, GIC demonstrated routinely lower levels of cytocompatibility throughout the three observation points compared with control cells and both MTA and BD treatments. Our results are in accordance with Makkawy., et al. (1998) who reported that GIC inhibited the growth of gingival fibroblasts and periodontal ligament cells [14].
Regarding the marginal adaptation the most important property of root end filling is to prevent bacteria and their products from diffusion from the root canal into periapical tissues and vice versa [15]. Our approach to assess the marginal adaptation of a filling material is to determine the gap size under a SEM which is a reasonable technique for the appraisal of marginal adaptation as a result of its high magnification and good resolution [16].

A great results of apical surgery procedure performed using ultrasonic tips have been accounted in several studies $[17,18]$. However, cracks have been observed after their usage in retro-cavities preparations. A previous study also related the utilization of ultrasonic tips with chipping of the cavity margins [19]. Burs were utilized in this study to avoid cracks especially in the thinnest walls of the root end cavity.

In the present study, the SEM observation (at $\times 500$ and $\times 1000$ ) of each half of the root-end-filled teeth of the three-different groups for the marginal adaptation showed the presence of gaps between retrograde materials and cavity wall in the most of cases. The gap (in terms of maximum length and width) was measured between material and dentinal wall on both sides (right and left) of specimens after longitudinal sectioning of prepared teeth under SEM at $\times 500$ and $\times 1000$. The higher magnifications were used to record the measurements more conveniently. The same method was used by Baranwal., et al. (2015) to study the marginal adaptation of grey MTA, white MTA, and Portland cement under SEM [20].

The SEM study of marginal adaptation of BD, MTA and GIC to dentin showed that there was no statistically significant difference between BD and MTA, This may be explained by the fact that both of them had similar composition with calcium silicate as their main constituent which expands by $0.2 \%-6 \%$ of its initial volume. This expansion significantly increases their sealing ability [21], while there was a statistically significant difference between both of them and GIC. These outcomes are as previously reported by Ravichandra., et al. (2014) who utilized confocal laser scaning microscopy to show the marginal adaptation between root dentin and retrofilling material utilizing BD and MTA contrasted and GI [22]. The probable reason for the increased mean gap size in GIC 
A Comparative Study of Biocompatibility and Marginal Adaptability of MTA, Biodentine, and Glass Ionomer Cement as Root -End Filling Materials (Comparative In-Vitro Study)

is that freshly mixed GIC shows difficulty in handling and is also sensitive to moisture. GIC may exhibit shrinkage upon setting with more voids [23].

Based on these results, it may be concluded that MTA and Biodentine display good cytocompatibility with normal fibroblast cells. Both did not significantly affect cell proliferation and can be classified as biocompatible retrograde filling materials, While GIC significantly affect fibroblasts proliferation and should be used carefully due to its cytotoxic effects.

Under SEM, concerning marginal adaptability, MTA and Biodentine showed less micro-gaps with the dentinal walls compared with GIC and they can be used successfully as retrograde filling materials thereby increasing the sealing ability and the life of the tooth.

\section{Conclusion}

Within the conditions of this study, it could be concluded that:

- $\quad$ Overall, both MTA and Biodentine show comparable and favorable cell viability on fibroblast-like cells.

- However, MTA shows a tendency to a consistent increase in viability up to 7 days.

- $\quad$ GIC shows the least cell viability overall the three observation points.

- $\quad$ MTA and Biodentine are significantly superior when compared to GIC in terms of marginal adaptation, when used as retrograde filling materials.

\section{Conflict of Interest}

The authors deny any conflicts of interest in this study.

\section{Bibliography}

1. Shahi Shahriar., et al. "Comparative investigation of marginal adaptation of mineral trioxide aggregate (MTA) and Portland cement as root-end filling materials: A scanning electron microscopy (SEM) study". African Journal of Biotechnology 10(2011):11.

2. Bidar Maryam., et al. "Comparative SEM study of the marginal adaptation of white and grey MTA and Portland cement". Australian Endodontic Journal: The Journal of the Australian Society of Endodontology Inc 33.1 (2007): 2-6.
3. Oliveira Helder Fernandes., et al. "Evaluation of marginal adaptation of root-end filling materials using scanning electron microscopy". Iranian Endodontic Journal 8.4 (2013): 182-186.

4. Almeida, Bernardo M., et al. "In vitro evaluation of dentin marginal adaptation of three root-end filling materials inserted with and without surgical microscope". Dental Press Endodontics 2(2012):20-25.

5. Stabholz, A., et al. "Marginal adaptation of retrograde fillings and its correlation with sealability". Journal of Endodontics 11.5 (1985): 218-223.

6. A Saberi Eshagh., et al. "Cytotoxic effects of mineral trioxide aggregate, calcium enrichedmixture cement, Biodentine and octacalcium pohosphate onhuman gingival fibroblasts". Journal of Dental Research, Dental Clinics, Dental Prospects 10.2 (2016): 75-80.

7. Mosmann T. "Rapid colorimetric assay for cellular growth and survival: application to proliferation and cytotoxicity assays". Journal of Immunological Methods 65.1-2 (1983): 55-63.

8. Keiser K., et al. "Cytotoxicity of mineral trioxide aggregate using human periodontal ligament fibroblasts". Journal of Endodontics 26.5 (2000): 288-291.

9. Camilleri, J., et al. "Biocompatibility of two commercial forms of mineral trioxide aggregate". International Endodontic Journal 37.10 (2004): 699-704.

10. Zhou, Hui-min., et al. "In vitro cytotoxicity evaluation of a novel root repair material”. Journal of Endodontics 39.4 (2013): 478-483.

11. Moghaddame-Jafari, Sasan., et al. "Effect of ProRoot MTA on pulp cell apoptosis and proliferation in vitro". Journal of Endodontics 31.5 (2005): 387-391.

12. Amin Suzan Abdul Waness., et al. "Comprative chemical and biological study of Portland cement and mineral trioxide aggregate as endodontic materials". Doctorate Degree Thesis, faculty of oral and dental medicine, Cairo University (2006). 
13. Liu Guangpeng., et al. "Tissue-engineered bone formation using human bone marrow stromal cells and novel beta-tricalcium phosphate". Biomedical Materials (Bristol, England) 2.2 (2007): 78-86.

14. Makkawy H A., et al. "Cytotoxicity of root perforation repair materials". Journal of Endodontics 24.7 (1998): 477-479.

15. Gartner A H and S O Dorn. "Advances in endodontic surgery". Dental clinics of North America 36.2 (1992): 357-378.

16. Al-Fouzan Khalid., et al. "Effect of acid etching on marginal adaptation of mineral trioxide aggregate to apical dentin: microcomputed tomography and scanning electron microscopy analysis". International Journal of Oral Science 4.4 (2012): 202207.

17. Chong, B S., et al. "The adaptation and sealing ability of lightcured glass ionomer retrograde root fillings". International Endodontic Journal 24.5 (1991): 223-232.

18. Zuolo M L., et al. "Prognosis in periradicular surgery: a clinical prospective study". International Endodontic Journal 33.2 (2000): 91-98.

19. Lloyd A., et al. "Microleakage of Diaket and amalgam in rootend cavities prepared using MicroMega sonic retro-prep tips". International Endodontic Journal 30.3 (1997): 196-204.

20. Baranwal Akash Kumar., et al. "An ex-vivo comparative study of root-end marginal adaptation using grey mineral trioxide aggregate, white mineral trioxide aggregate, and Portland cement under scanning electron microscopy". Journal of Conservative Dentistry: JCD 18.5 (2015): 399-404.

21. Prati Carlo, and Maria Giovanna Gandolfi. "Calcium silicate bioactive cements: Biological perspectives and clinical applications". Dental Materials : Official Publication of the Academy of Dental Materials 31.4 (2015): 351-370.

22. P V Ravichandra., et al. "Comparative Evaluation of Marginal Adaptation of Biodentine(TM) and Other Commonly Used Root End Filling Materials-An Invitro Study". Journal of Clinical and Diagnostic Research : JCDR 8.3 (2014): 243-245.
23. Ansari Shuja Riaz., et al. "A comparison of sealing capabilities of amalgum, GIC and zinc oxide eugenol cement when used as retro grade filling materials (in vitro study)". Journal of Ayub Medical College, Abbottabad: JAMC 15.3 (2003): 43-46.

\section{Assets from publication with us}

- Prompt Acknowledgement after receiving the article

- Thorough Double blinded peer review

- Rapid Publication

- Issue of Publication Certificate

- High visibility of your Published work

Website: www.actascientific.com/

Submit Article: www.actascientific.com/submission.php Email us: editor@actascientific.com

Contact us: +919182824667 